\title{
Nurses' Knowledge Regarding Heart Failure Education Principles in Erbil Teaching Hospital
}

Bootan Hasan Ahmed ; Department of Nursing, College of Nursing, Hawler Medical University, Erbil, Iraq.

Sideeq Sadir Ali; Department of Nursing, College of Nursing, Hawler Medical University, Erbil, Iraq.

(Correspondence: sideeq.sadir@nur.hmu.edu.krd)

Vian Afan Naqshbandi; Department of Nursing, College of Nursing, Hawler Medical University, Erbil, Iraq.

Ribwar Arsalan Mohammed; Department of Nursing, College of Nursing, University of Rparin, Sulaimaniya, Iraq.

\section{ABSTRACT}

Background and objective: Heart Failure is a major public health problem often associated with a decreased quality of life and high mortality rate. To optimize the quality of management and support patients to care for themselves in their own home, they need to be welleducated about all aspects of the heart failure. This study aims to investigate nurses' knowledge regarding the treatments that can be taught to heart failure patients to improve self-care.

Methods: Cross-sectional study, 64 nurses out of 85 working at three public hospitals in Erbil City took part, the data was collected from 15th February to 15th March, 2017 through interviews using a questionnaire schedule. The data was analyzed using Statistical Package for the Social Science (SPSS) program version 20.

Results: Majority of the participants were young (87.6\% within the range of 21-40), male (62.5\%), and graduated with a technical diploma (60.9\%). More than half of them $(53.1 \%)$ have between 1-5 years of nursing experience, $50 \%$ of the nurses work in the Surgical Specialty Hospital - Cardiac Centre and $43.8 \%$ of them have general knowledge of Cardiac care. The majority of participants achieved a good knowledge score (70.3\%). There was a significant association between level of knowledge of nurses working in the Surgical Specialty Hospital - Cardiac Centre and Rizgary Teaching Hospital, while few of them are in Hawler Teaching Hospital (53.3\%, 26.7\% and 20\% respectively P $<0.002$ ).

Conclusion: The study concluded that the nurses have good knowledge score, but still need continuous knowledge and practical training to educate patients regarding heart failure. High level of significance was found between the levels of knowledge and the working area.

Keywords: Nurse; Knowledge; Heart failure; Education Principles.

Received: $2 / 9 / 2017$

Accepted: $28 / 10 / 2017$

Published: 5/5/2018

\section{INTRODUCTION}

Heart failure (HF) has become a major public health problems, with the prevalence of over 23 million worldwide [1]. It is a condition in which the heart is unable to adequately pump blood throughout the body or unable to prevent blood from "backing up" into the lungs [2]. Most of HF patients are not looked after by specialists and have little knowledge of their condition and its treatment [1]. Therefore, it is common reason for hospital readmissions, and subsequently, a major contributor to rising health care costs [3]. It has also been reported that Medicare spends more money on heart failure treatment than it does 
on Mls and all forms of cancer combined [4]. Thirty to forty percent of HF patients are readmitted within six months of their previous hospitalization [5]. Hence, education of heart failure patients and their families is critical. Failure of these patients to comply with physicians and other healthcare providers' instructions is sometimes a cause of heart failure exacerbation. A significant reason for patient's failure to comply is lack of understanding as well as poor discharge planning that are associated with improved patient outcomes [6].

Therefore, HF patients need to be welleducated on various aspects of HF so that they can be successful in their selfmanagement of $\mathrm{HF}$, this will enable them to manage their disease in their home environment. A number of studies have been conducted regarding guidelines and heart failure management among nurses. A study examined nurse's knowledge of heart failure education topics at a regional Midwestern Hospital [3]. In addition, six other studies have assessed knowledge of nurse regarding HF education principles $[7,8,9,10$, $11,12]$. Although, such studies have provided important information on nurse's knowledge regarding $\mathrm{HF}$ topics that need to be taught to HF patients, however, HF patients are not homogenous in their demography, disease pathogenesis, treatment protocol, and side effects of the treatments and level of education. Nurses can play an essential role in educating $\mathrm{HF}$ patients on HF self-care. This education enables patients to successfully manage their HF at home and minimize hospital readmission [3]. Therefore, the aim of this study was to investigate nurses' knowledge regarding self-care of patients with $\mathrm{HF}$ and to find out association between nurses' knowledge with their socio-demographic characteristics.

\section{METHODS}

This cross-sectional study was carried out in three public hospitals (medical word of Rizgary Teaching and Hawler Teaching Hospital also three units of the Surgical Specialty Hospital - Cardiac Centre; surgical, cardiac catheterization and outpatient unit) at Erbil City/ Kurdistan Region during the period from 15th February to 15th March, 2017. Among the 85 nurses that worked at medical words of Rizgary Teaching Hospital, Surgical Specialty Hospital Cardiac Centre and Hawler Teaching Hospital, 64 participated. The first hospital was Rizgary Teaching Hospital, during conducting this study the hospital was under reconstruction and 18 nurses accept to participate in this study from 21 . The second hospital was Surgical Specialty Hospital - Cardiac Center in which 45 nurses were asked to participate; 32 nurses here agreed to participate in this study. The third hospital was Hawler Teaching hospital, in this hospital nurses who work in coronary care unit and medical ward were asked to be involved in this study, 18 nurses confirmed their participation out of 22 . Inclusion criteria were; nurses who have experience in delivering direct care to $\mathrm{HF}$ patients, and have at least one of the following levels of education Diploma, Bachelor Degree, Master of Science or PhD in nursing. Nurses who did not agree to participate in this study or did not have experience of caring of HF patients were excluded. This study was approved by the Scientific and Ethics Committee of the College of Nursing at Hawler Medical University. Institutional approval for conducting the study was also obtained from General Directorate of Health in Erbil and the three hospitals mentioned above. Confidentiality regarding personal issues of the persons was ensured. At first a self-assessment of the nurses' knowledge of heart failure was 
conducted. The questionnaire consisted of 19-question with two options "true" and "false" which measured nurses' knowledge of heart failure topics [5]. Questions were about diet (3 questions), fluid or weight monitoring (6 questions), signs and symptoms of worsening heart failure (6 questions), medications (2 questions), and exercise (2 questions). Socio-demographic characteristics of the study sample were collected including age, level of education and years of experience working with heart failure patients. The final question was an open-ended question to explore the topics related to heart failure for which nurses would like more education. As a comparative measure of the knowledge of heart failure education principles, the overall true score was expected to be $87.5 \%$ or greater for nurses who regularly cared for heart failure patients-this means 17 to 18 correct answers out of 20 possible [7]. For the first the questions regarding $\mathrm{HF}$ knowledge nurses' responses to the questions were divided into three categories 'Poor knowledge', 'Good knowledge' and 'High knowledge'. The score of poor knowledge ranged from $1 \%-33 \%$, good knowledge ranged from $34 \%-67 \%$. High knowledge' ranged from $68 \%$ - 100\%. Data was then entered into Statistical Package for the Social Science (SPSS), version 20 and analyzed by applying two statistical approaches: Descriptive data analysis (frequency, percentage, mean) and inferential data analysis (Chi-square test).

\section{RESULTS}

The majority of the study samples (43.8\%) were within the both ranges 21-30 and $31-40$ years old. The mean age and standard deviation ( $M \pm S D$ ) of the nurses were $32.47 \pm 7.176$. Majority of the study participants were male $(62.5 \%)$. The years of experience of more than half of the nurses $(53.1 \%)$ with the heart failure patients in hospital were between $1-5$ years. With regards to educational level, most of the study sample graduated from a nursing institute $(60.9 \%)$ (Table 1$)$. in addition, half of the participants (50\%) worked in the Surgical Specialty Hospital Cardiac Centre. Finally $43.8 \%$ of nurses thought that they had good understanding of heart failure education topics.

Table 2 shows the knowledge levels of the 64 participants regarding heart failure education principles. The highest correct knowledge score for the first section was for the question "Swelling of the abdomen may indicate retention of excess fluid due to worsening heart failure" (75\%), While the lowest knowledge score was for the question "Patients with heart failure should decrease activity and most forms of active exercise should be avoided" (10.9\%). Regarding second section the highest correct knowledge score was for the question "new onset or worsening of fatigue" (78.1\%) while the lowest knowledge score was for the question "Dizziness or lightheadedness when arising that disappears within 10-15 minutes" (46.9\%).

Table 3 focuses on the overall knowledge of the nurses regarding heart failure; the table shows that majority of the nurses had a good knowledge and received average score $70.3 \%$, while $9.4 \%$ had poor knowledge. It also demonstrates that only $20.3 \%$ of the nurses had high knowledge levels.

Table 4 illustrates relationships between the nurses overall knowledge levels and their socio-demographic data. In general, there was no significant association between the level of knowledge and the socio-demographic characteristics of the nurses except "Place of work or hospital" which was significantly higher for those nurses working in the Surgical Specialty Hospital - Cardiac Centre and Rizgary 
Table 1: Sociodemographic characteristics

\begin{tabular}{ccr}
\hline $\begin{array}{c}\text { Socio-demographic } \\
\text { characteristics }\end{array}$ & \multicolumn{2}{c}{$\mathbf{N}=\mathbf{6 4}$} \\
\cline { 2 - 3 } & $\mathbf{F}$ & $\mathbf{\%}$ \\
\hline Age group (years) & 28 & $(43.8)$ \\
$21-30$ & 28 & $(43.8)$ \\
$31-40$ & 8 & $(12.5)$ \\
$41>$ & $32.47 \pm 7.176$
\end{tabular}

Gender

$\begin{array}{ll}\text { Male } & 40 \\ \text { Female } & 24\end{array}$

Years of experience with heart failure

$1-5$ years

$6-11$ years

19

12-17 years

Above 18 years

Educational levels

$\begin{array}{lc}\text { Associated nurse } & 5 \\ \text { Technical Diploma } & 39 \\ \text { Baccalaureate } & 17 \\ \text { Master } & 3\end{array}$

Place of work

$\begin{array}{ll}\begin{array}{l}\text { Rizgary Teaching } \\ \text { Hospital }\end{array} & 18 \\ \text { Hawler Teaching } & 14 \\ \text { Hospital } & \\ \text { Surgical Specialty } & 32 \\ \text { Hospital - Cardiac } & \\ \text { Centre } & \end{array}$

Good understanding of heart failure education topics

\begin{tabular}{lcc} 
Strongly Agree & 2 & $(3.1)$ \\
Agree & 28 & $(43.8)$ \\
Neither Agree or & 24 & $(37.5)$ \\
Disagree & & \\
Disagree Strongly & 6 & $(9.4)$ \\
Disagree & 4 & $(6.3)$ \\
$\quad$ Total & $\mathbf{6 4}$ & $\mathbf{( 1 0 0 )}$ \\
\hline
\end{tabular}

and Rizgary Teaching Hospital than Hawler Teaching Hospital (53.3\%, 26.7\% and 20\% respectively P-value $<0.002$ ).

\section{DISCUSSION}

This study assessed the level of knowledge of sixty four nurses in three public hospitals in Erbil City. Educational support by a nurse for heart failure patient in a hospital and at home significantly increases self-care behavior [13]. Out of 19 questionnaire items; the highest knowledge scored was for the question "If patients take their medications as directed and follow the suggested lifestyle" in part one and the lowest score was in the question "Patients with heart failure should decrease activity and most forms of active exercise should be avoided" also from part one. In general, the participants answered most of the questions in part one (Knowledge regarding heart failure education principles) incorrectly and answered part two of the questionnaire (Knowledge regarding some of the signs and symptoms significant or not significant for heart failure patient) mostly correctly. The fact that more questions were answered incorrectly than correctly, may be because the nurses did not do any training courses to improve their knowledge or neglected to obtaining the knowledge, because most of them (43.8\%) were happy with their level of knowledge, or it could be due to the fact that most of them (53.1\%) had low levels of experience working with heart failure patients in hospital. Standfuss, (2012), reported; Nurses have important position in educating patients regarding heart failure, also they are in a key position to educate patients to effectively manage their heart failure independently [3]. The results of this study was supported by the cross-sectional, descriptive study that conducted by Knopp, (2009) in a western Montana at US, which 
Table 2: Knowledge of nurses regarding heart failure education principles

\begin{tabular}{|c|c|c|c|c|}
\hline \multirow[b]{2}{*}{ Knowledge of nurses } & \multicolumn{2}{|c|}{ False } & \multicolumn{2}{|c|}{ True } \\
\hline & $\mathbf{F}$ & $\%$ & $\bar{F}$ & $\%$ \\
\hline \multicolumn{5}{|l|}{$\begin{array}{l}\text { Knowledge regarding heart failure education } \\
\text { principles }\end{array}$} \\
\hline $\begin{array}{l}\text { If patients feel thirsty, it is OK to remove fluid limits and } \\
\text { allow them to drink. }\end{array}$ & 34 & $(53.1)$ & 30 & $(46.9)$ \\
\hline $\begin{array}{l}\text { As long as no salt is added to foods, there are no dietary re- } \\
\text { strictions for patients with HF. }\end{array}$ & 26 & $(40.6)$ & 38 & $(59.4)$ \\
\hline $\begin{array}{l}\text { It is OK to use potassium-based salt substitutes (like "No- } \\
\text { Salt" or "Salt Sense") to season food. }\end{array}$ & 32 & $(50)$ & 32 & $(50)$ \\
\hline $\begin{array}{l}\text { Lean deli meats are an acceptable food choice as part of the } \\
\text { patient's diet. }\end{array}$ & 46 & (71.9) & 18 & $(28.1)$ \\
\hline $\begin{array}{l}\text { Coughing and nausea/poor appetite are common symptoms } \\
\text { of advanced heart failure. }\end{array}$ & 22 & $(34.4)$ & 42 & $(65.6)$ \\
\hline $\begin{array}{l}\text { Patients with heart failure should decrease activity and most } \\
\text { forms of active exercise should be avoided. }\end{array}$ & 57 & $(89.1)$ & 7 & $(10.9)$ \\
\hline $\begin{array}{l}\text { When patients have aches and pains, aspirin and non- } \\
\text { steroidal anti-inflammatory. }\end{array}$ & 26 & $(40.6)$ & 38 & $(59.4)$ \\
\hline $\begin{array}{l}\text { If patients take their medications as directed and follow the } \\
\text { suggested lifestyle. }\end{array}$ & 13 & $(20.3)$ & 51 & (79.7) \\
\hline $\begin{array}{l}\text { If a patient adds extra pillows at night to relieve shortness of } \\
\text { breath, this does not. }\end{array}$ & 48 & $(75)$ & 16 & $(25)$ \\
\hline $\begin{array}{l}\text { If a patient wakes up at night with difficulty breathing, and } \\
\text { the breathing difficulty is relieved by getting out of bed and } \\
\text { moving around, this does not mean that the HF. }\end{array}$ & 40 & $(62.5)$ & 24 & $(37.5)$ \\
\hline $\begin{array}{l}\text { Swelling of the abdomen may indicate retention of excess } \\
\text { fluid due to worsening HF. }\end{array}$ & 16 & $(25)$ & 48 & $(75)$ \\
\hline $\begin{array}{l}\text { Once the patient's HF symptoms are gone, there is no need } \\
\text { for daily obtaining. }\end{array}$ & 32 & (50) & 32 & $(50)$ \\
\hline $\begin{array}{l}\text { If the patient gains more than } 3 \text { pounds in } 48 \text { hours without } \\
\text { other HF symptoms, they should not be concerned. }\end{array}$ & 35 & $(54.7)$ & 29 & $(45.3)$ \\
\hline When assessing weight results, today's weight should be & 17 & $(26.6)$ & 47 & (73.4) \\
\hline
\end{tabular}
compared with the patient's weight from yesterday, not the patient's ideal or "dry" weight.

\section{Knowledge regarding some of the sing and symptom sig- nificant or not significant for heart failure patient.}

BP recording of 80/56 without any HF symptoms.

$27 \quad(42.2) \quad 37$

Weight gain of 3 pounds in 5 days without symptoms.

$28 \quad(43.8) \quad 36$

Dizziness or lightheadedness when arising that disappears

$30 \quad(46.9) \quad 34$

within 10-15 minutes.

New onset or worsening of fatigue.

$14 \quad(21.9) \quad 50$

New onset or worsening of leg weakness or decreased ability

18

(28.1) $\quad 46$
to exercise. 
Table 3: Overall knowledge of the nurses regarding heart failure

\begin{tabular}{ccc}
\hline \multirow{2}{*}{$\begin{array}{c}\text { Overall } \\
\text { Knowledge }\end{array}$} & \multicolumn{2}{c}{$\mathbf{N = 6 4}$} \\
\cline { 2 - 3 } & $\mathrm{F}$ & $\%$ \\
\hline Poor knowledge & 6 & $(9.4)$ \\
Good knowledge & 45 & $(70.3)$ \\
High knowledge & 13 & $(20.3)$ \\
\hline
\end{tabular}

demonstrated that nurses working in a western Montana hospital may not be sufficiently knowledgeable regarding the HF education guidelines [5]. The results of this study do not correlate with the study of Fowler, (2012), where the mean score of nurses' knowledge was $80 \%$ on the pretest with 16 correct answers out of $20(80 \%)$ [14]. the nurses had a good knowledge

Table 4: Association between nurses' overall knowledge and socio-demographic data

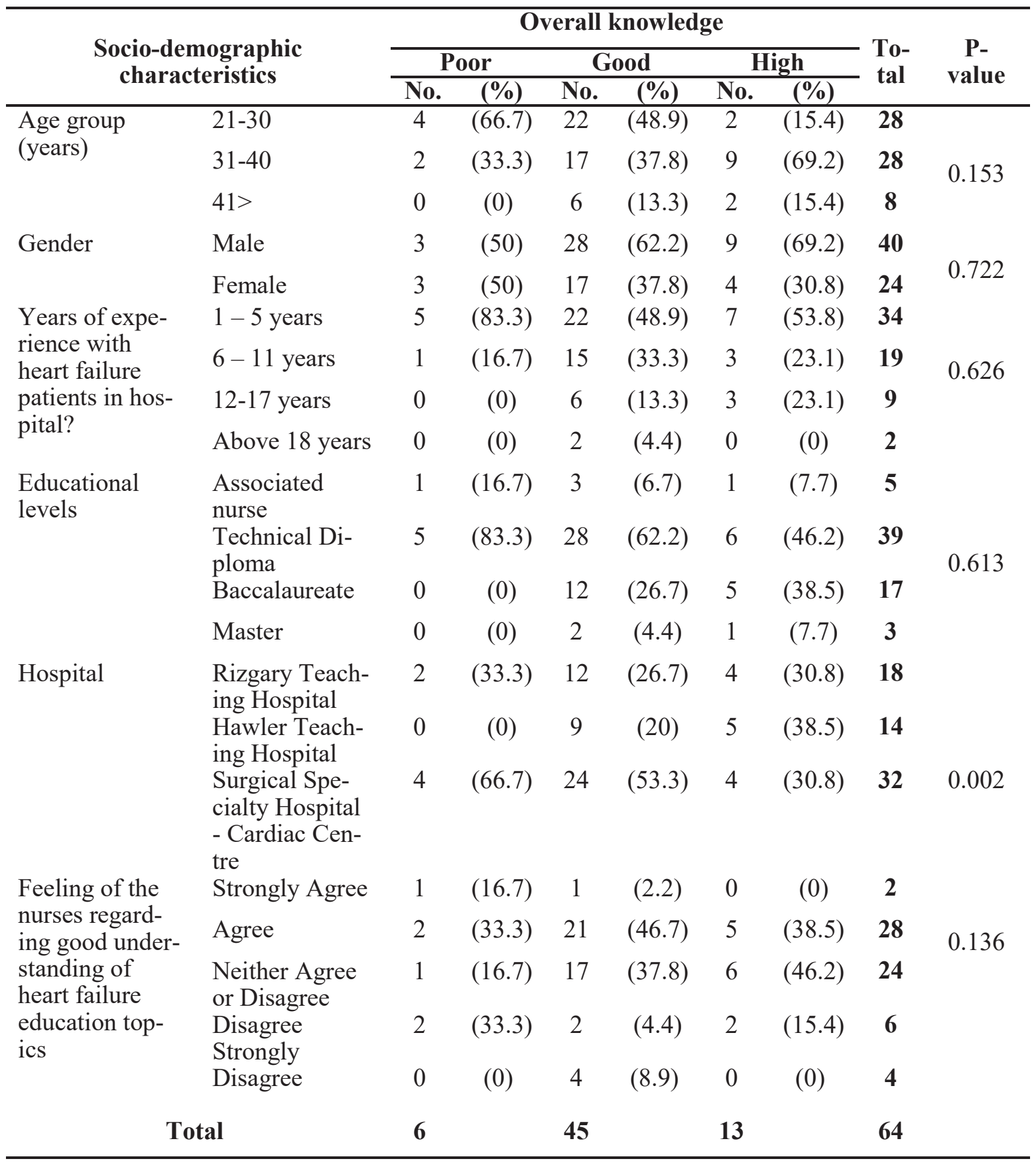


in relation to the signs and symptoms of $\mathrm{HF}$, but in terms of how to education the patients the knowledge level of participants was low. With reference to the knowledge of the participants regarding heart failure (table 3); the majority of them had a good level of knowledge at $70.3 \%$, $20.3 \%$ had high knowledge and only $9.4 \%$ of them had poor knowledge. This could be due to fact that the majority of the nurses were interested in receiving HF information, but don't have opportunities to improve their knowledge. It also could be due to the level of education of majority of participants which was at the level of nursing institute (60.9\%). The study revealed that nurses are key providers of patient education during admission and predischarge, as well as through directed teaching sessions which in turn improve clinical outcomes and reduce cost of care $[15-17,7]$. The result of this study is support that of Garris (2014) a quasiexperimental program development with a pretest, intervention, and post-test to increase nurses' knowledge regarding HF education; pre-tests scores ranged from 6090 out of possible 100, with a mean score of $73.3 \%$ [18]. The results also agree with the study conducted by Willette et al. (2014) which surveyed 49 nurses who regularly provided care to patients with $\mathrm{HF}$ at a hospital in the southeastern United States; here the mean HF self-management knowledge score was 15.97 (79.85\% correct) [19]. Conversely, the results are below that of the study by Hart et al. 2010 on 122 nurses from a healthcare system located in the Southeastern USA, where the nurses were highly knowledgeable about multiple areas of HF with, $90 \%$ of the sample correctly answering the item [20].Regarding the relationship between the overall knowledge of the nurses with socio-demographic data; there was no any significant association noticed between of knowledge and the nurses educational level in the study groups [3]. overall level of knowledge with socio-demographic characteristics except place of work, This may be due to the low number of the nurses who participated in this study from Rizgary and Hawler Teaching hospital. In addition, $50 \%$ of the participants were in the Surgical Specialty Hospital - Cardiac Centre. The results correlate with the study conducted by the Standfuss (2012); where no statistically significant difference found between overall mean score.

\section{Limitations of the study}

The result of the study showed no statistically significant relationship between the level of knowledge and majority of the variables. This may be due to limitations such as; low sample size of participants due to some of the eligible nurses refusing to participate in the study. In addition it was difficult on occasions to arrange appointments with the nurses. Finally, the nurses had insufficient information due to lack of resources for receiving information.

\section{CONCLUSION}

The study concluded that the nurses had a good level of knowledge, but generally did not have enough information about heart failure. Most of the nurses did not interact well with the patients in giving information, and generally no significant relationship was found between the nurse's level of knowledge and other characteristics, except from the place of work.

\section{CONFLICTS OF INTEREST}

There are no conflicts of interest and sources of financial support for any of the authors. 


\section{REFERENCES}

[1] Blue L, Lang E, McMurray JJ, Davie AP, McDonagh TA, Murdoch DR, et al. Randomised controlled trial of specialist nurse intervention in heart failure. Bmj. 2001 Sep 29; 323(7315):715-8.

[2] Center for Disease Control. Heart failure fact sheet. 2006; Available from: https://www.cdc.gov/dhdsp/ data_statistics/fact_sheets/docs/fs_heart_failure.pdf [Accessed: 1 May 2017].

[3] Standfuss CJ. Nurses' Knowledge of Heart Failure Education Topics at a Regional Midwestern Hospital (Doctoral dissertation, Minnesota State University, Mankato). 2012; Available from: http:// cornerstone.lib.mnsu.edu/etds [Accessed: 1 May 2017].

[4] Massie BM, Shah NB. Evolving trends in the epidemiologic factors of heart failure: rationale for preventive strategies and comprehensive disease management. American heart journal. 1997 Jun 1; 133(6):703-12. doi: 10.1016/S0002-8703(97)70173-X [Accessed: 7 June 2017].

[5] Knopp AM. Nurses' knowledge of heart failure guidelines in a Western Montana hospital (Doctoral dissertation, Montana State University-Bozeman, College of Nursing). 2009; Available from: http:// citeseerx.ist.psu.edu/viewdoc/download? doi=10.1.1.552.3574\&rep=rep1\&type=pdf [Accessed: 1 May 2017].

[6] Bonow RO, Bennett S, Casey DE, Ganiats TG, Hlatky $M A$, Konstam MA, et al. ACC/AHA clinical performance measures for adults with chronic heart failure: a report of the American College of Cardiology/ American Heart Association task force on performance measures (writing committee to develop heart failure clinical performance measures) endorsed by the Heart Failure Society of America. Journal of the American College of Cardiology. 2005 Sep 20; 46 (6):1144-78. Available from: http:// circ.ahajournals.org/cgi/content/full/112/12/1853 [Accessed: 1 May 2017].

[7] Albert NM, Collier S, Sumodi V, Wilkinson S, Hamme $J P$, Vopat L, et al. Nurses's knowledge of heart failure education principles. Heart \& Lung: The Journal of Acute and Critical Care. 2002 Apr 30; 31(2):102-12.

[8] Fonarow GC, Stevenson LW, Walden JA, Livingston NA, Steimle $A E$, Hamilton MA, et al. Impact of a comprehensive heart failure management program on hospital readmission and functional status of patients with advanced heart failure. Journal of the American College of Cardiology. 1997 Jul 31; 30(3):725-32.

[9] Koelling TM, Johnson ML, Cody RJ, Aaronson KD. Discharge education improves clinical outcomes in patients with chronic heart failure. Circulation. 2005 Jan 18; 111(2):179-85.

[10] Labeau S, Vandijck DM, Claes B, Van Aken P, Blot SI, Executive Board of the Flemish Society for Critical Care Nurses. Critical care nurses' knowledge of evidence-based guidelines for preventing ventilatorassociated pneumonia: an evaluation questionnaire. American Journal of Critical Care. 2007 Jul 1; 16
(4):371-7

[11] Lakasing E, Francis H. Diagnosis and management of heart failure: Edin Lakasing and Heather Francis discuss the causes, features, investigation and management of heart failure. Primary Health Care. 2006 Jun 1; 16(5):36-9.

[12] Nicholas M. Heart failure: pathophysiology, treatment and nursing care. Nursing standard. 2004 Nov 30; 19(11):46-52.

[13] Jaarsma T, Halfens R, Huijer Abu-Saad H, Dracup K, Gorgels T, Van Ree J, et al. Effects of education and support on self-care and resource utilization in patients with heart failure. European heart journal. 1999 May 1; 20(9):673-82.

[14] Fowler S. Improving community health nurses' knowledge of heart failure education principles: a descriptive study. Home Healthcare Now. 2012 Feb 1; 30(2):91-9. Available from: www.homehealthcarenurseonline.com [Accessed: 7 June 2017].

[15] Heart Failure Society of America. Executive summary: HFSA 2010 comprehensive heart failure practice guideline. Journal of Cardiac Failure. 2010 Jun 30; 16(6):475-539.

[16] Mitchell KM. Rural nurse knowledge of heart failure self-care principles (Doctoral dissertation, Montana State University-Bozeman, College of Nursing). 2014; Available from: http://scholarworks.montana.edu/ xmlui/handle/1/3396 [Accessed: 7 June 2017].

[17] McCauley KM, Bixby MB, Naylor MD. Advanced practice nurse strategies to improve outcomes and reduce cost in elders with heart failure. Disease Management. 2006 Oct 1; 9(5):302-10.

[18] Garris AM. Nurses' Knowledge Related to Heart Failure Essentials. 2014; Available from: http:// digitalcommons.ric.edu/school_of_nursing/42 [Accessed: 7 June 2017].

[19] Willette EW, Surrells D, Davis LL, Bush CT. Nurses' Knowledge of Heart Failure Self-Management. Progress in cardiovascular nursing. 2007 Sep 1; 22 (4):190-5.

[20] Hart PL, Spiva L, Kimble LP. Nurses' knowledge of heart failure education principles survey: a psychometric study. Journal of clinical nursing. 2011 Nov 1; 20(21-22):3020-8. Available from: doi:10.1111/ j.1365-2702.2011.03717.x. [Accessed: 7 June 2017]. 